\title{
Metastatic Colorectal Cancer: From Improved Survival to Potential Cure
}

\author{
David J. Gallagher Nancy Kemeny \\ Gastrointestinal Oncology Service, Division of Solid Tumor Oncology, Department of Medicine, Memorial \\ Sloan-Kettering Cancer Center and Joan and Sanford Weill Medical College of Cornell University, New York, N.Y., USA
}

\section{Key Words}

Metastatic colorectal cancer - Resectability · Curative intent

\begin{abstract}
Context: The treatment of colorectal cancer has improved considerably in recent years, but it remains the second commonest cause of cancer deaths in men and women in the United States. Better therapies have resulted in prolonged median survival for patients with metastatic disease and a select number of patients can now be cured. Evidence Acquisition: We conducted a computerized search using PubMed and Google Scholar for reports published between January 1993 and August 2009 using mesh headings and key words relating to the treatment of colorectal cancer. If reports identified by these criteria referred to other papers not in the initial search, then these were also reviewed if relevant to metastatic colorectal cancer (MCRC). Results: Seven new chemotherapy agents have been licensed for the treatment of advanced colorectal cancer, with associated improved median survival from 5 months to 2 years. Complete responses are rare with systemic chemotherapy alone, but higher overall response rates to systemic and intrahepatic chemotherapies have enabled initially unresectable patients to undergo potentially curative surgical resection of
\end{abstract}

metastases. Improved surgical expertise together with the adjunctive use of radiofrequency ablation has further expanded the definition of resectability. Advances in the understanding of tumor biology have resulted in the development of clinically useful biomarkers and the emergence of active biological therapies. Conclusions: The multidisciplinary management of MCRC incorporating improved systemic and local therapies continues to improve median survival and enlarge the cohort of patients that can be approached with curative intent. Recent technological advances have facilitated a better understanding of tumor biology that promises continued advancements in patient care.

Copyright $\odot 2010$ S. Karger AG, Basel

\section{Introduction}

The management of patients with metastatic colorectal cancer (MCRC) has advanced in recent years, with many of the developments reflecting changes in general medical oncology practice, and a multidisciplinary approach is now the norm. Seven new drugs have been licensed, and predictive markers to guide treatment decisions are available. Improved surgical techniques and regional therapies such as hepatic arterial infusion

\section{KARGER}

Fax +4161306 1234 E-Mail karger@karger.ch www.karger.com
(C) 2010 S. Karger AG, Basel $0030-2414 / 10 / 0784-0237 \$ 26.00 / 0$

Accessible online at:

www.karger.com/ocl
Nancy Kemeny, MD

Department of Medicine, Memorial Sloan-Kettering Cancer Center 1275 York Avenue

New York, NY 10021 (USA)

Tel. +1 212639 8068, Fax +1 212794 7186, E-Mail kemenyn@ mskcc.org 
chemotherapy and radiofrequency ablation (RFA) have improved the outlook for patients with colorectal liver metastases (CLM). Median survival times are longer, and an increasing minority of select patients is actually cured. A better understanding of the biology of colorectal cancer initiated these improvements in patient management, and recent technological advances have provided the tools for further progress.

\section{Methods}

We conducted a computerized search using PubMed and Google Scholar for reports published between January 1993 and August 2009 using mesh headings and key words relating to the treatment of colorectal cancer. If reports identified by these criteria referred to other papers not in the initial search, then these were also reviewed if relevant to MCRC. The following search terms were used: MCRC, metastatic colon cancer, advanced colorectal cancer, advanced colon cancer, colorectal liver metastases, CLM, colorectal hepatic metastases, colorectal hepatic metastasis, chemotherapy, biologic therapy, systemic treatment, fluorouracil, irinotecan, oxaliplatin, cetuximab, panitumumab, bevacizumab, surgery, hepatic arterial infusion, radiofrequency ablation, biomarker, KRAS, UGTA1, genetics, genome-wide association study. The references of all identified relevant studies were also searched for additional potentially relevant publications.

\section{How Do Colon Cancer Cells Metastasize?}

The 'seed and soil' hypothesis was proposed in 1889 to explain the pathogenesis of metastasis and stated that 'seeds are carried in all directions; but they can only live and grow if they fall on congenial soil' [1]. Mechanical factors play a role in MCRC; the mesenteric circulation and fenestrated capillaries of the liver facilitate hepatic metastasis [2, 3], but in the 1970s definitive proof of Paget's 'seed and soil' hypothesis emerged when Hart and Fidler [4] and Fidler and Poste [5] demonstrated that while metastatic cells may reach a number of organs, metastases develop in a select few.

Metastasis appears to develop in three steps: the cells leave the primary site and disseminate (initiation), before invading new parenchyma (progression), and finally colonizing a distant organ (virulence) [6]. Many genetic and epigenetic events govern this process $[6,7]$. The transition of a colorectal cancer from invasive carcinoma has been well described [8], and involves mutations in the Wnt pathway through APC gene inactivation or B-catenin activation [9], followed by KRAS activation [10], PI3K acti- vation [11], TP53 inactivation [12], and loss of the transforming growth factor- $\beta$ tumor suppressor pathway [13]. The remaining mutations required to establish a macrometastasis are not well understood and may vary not just between malignancies, but also between individuals with the same primary tumor. The relatively quick metastasis of some colorectal tumors suggests that the required mutations may be obtained by certain cells early in their development, whereas other metastases take years to develop. Identification of markers for this differential biology would enable unique treatment of different tumors and personalized management for patients.

\section{Systemic Treatment of MCRC}

\section{Fluorouracil and the Beginning of Progress}

Targeted therapy is not a new concept in colorectal cancer. Fluoropyrimidines, whose target is thymidylate synthase, were introduced in 1957 at a time when median survival from MCRC was less than 6 months [14, 15]. More than 50 years later, 5 -fluorouracil (5-FU) remains the cornerstone of systemic therapy, but median overall survival (OS) now exceeds 2 years with combination therapies (table 1). Bolus 5-FU in combination with leucovorin (LV), a folate that stabilizes the binding of the drug to thymidylate synthase [16], improves OS by approximately 5 months over best supportive care $[17,18]$, and infusion regimens have improved survival with an improved toxicity profile [19]. Two oral fluoropyrimidines, capecitabine and S-1, have been introduced, further ensuring that 5-FU remains an essential component of current regimens [20-24]. Genetic and epigenetic factors that contribute to the efficacy and toxicity of 5-FU have been identified [25-27]. Many molecular pathways involved in drug metabolism (e.g. dihydropyrimidine dehydrogenase - low levels increase toxicity), drug target (thymidylate synthase - high levels decrease response), and DNA repair pathways likely interact but do not predict outcome [28-32].

\section{Irinotecan, Oxaliplatin and Combination Regimens}

Combination regimens of infusion 5-FU with either oxaliplatin (FOLFOX) or irinotecan (e.g. FOLFIRI) form the backbone of current treatments for MCRC to which a biologic agent is often added. Irinotecan was confirmed as an active agent in MCRC when its combination with infusion 5-FU/LV produced significant improvements in response rate (RR) $(35 \%$ vs. $22 \%$, p < 0.005$)$, time to progression (TTP) (6.7 vs. 4.4 months, $\mathrm{p}<0.001)$, and OS 
(17.4 vs. 14.1, $\mathrm{p}=0.031$ ), compared to 5-FU/LV alone [33]. Irinotecan is metabolized to its active metabolite, SN-38, by the UGT1A enzymes, and the UGT1A locus can be used to predict the risk of neutropenia with treatment [34-36]. The NCCTG/Intergoup trial N9741 established oxaliplatin as an active agent in MCRC, demonstrating superiority for infusion 5-FU/LV plus oxaliplatin (FOLFOX4) over IFL, a combination of irinotecan and bolus 5-FU/LV (RR: 45 vs. $31 \%$, TTP: 8.7 vs. 6.9 months and median OS: 19.5 vs. 15 months) [37]. The combination of capecitabine and oxaliplatin (XELOX) has similar activity to FOLFOX4 (progression-free survival, PFS, 8.0 vs. 8.8 months, and OS 19.8 vs. 19.6 months, respectively) $[38,39]$.

Survival of patients with MCRC appears to be determined by exposure to all three active agents, and the sequence of treatment may be less important [40]. Further improvements in RR have been reported with the threedrug combination of 5-FU, oxaliplatin and irinotecan (FOLFOXIRI) compared with FOLFIRI (60\% vs. 34\%, $\mathrm{p}<0.0001)$ which translated into improved PFS (9.8 vs. 6.9 months, $\mathrm{p}=0.0006)$, OS (22.6 vs. 16.7 months, $\mathrm{p}=$ 0.032 ), and complete resection rates (R0) (36 vs. $12 \%$; $\mathrm{p}=$ 0.017 ) [41]. However, toxicity is greater with the threedrug combination, and physician preference and desired outcome often decide treatment choice with data supporting sequential single-agent therapy in addition to combination therapy with FOLFIRI, FOLFOX, FOLFOXIRI and XELOX [42-46].

Patients with MCRC are typically treated for prolonged time periods, and schedule variations have been investigated to diminish toxicity and allow an optimal quality of life on treatment. Neuro- and hematologic toxicities most commonly limit treatment with oxaliplatin, while hematologic toxicity and diarrhea are the commonest treatment-limiting toxicities with irinotecan. Omission of oxaliplatin from FOLFOX for a period of twelve 2-week cycles reduces neurotoxicity without affecting efficacy [47], but 5-FU/LV must be maintained as a complete break from treatment can substantially compromise survival [48]. A 'stop-and-go' approach with FOLFIRI appears feasible based on the results of a randomized phase II study that demonstrated similar efficacy for a ' 2 months on -2 months off' regimen compared with continuous treatment [49].

Treatment of Metastatic Colorectal Cancer

\section{The Addition of Biologics: The Benefits of Improved Understanding of Colorectal Cancer Biology}

Three biological agents have been licensed for the treatment of colorectal cancer: bevacizumab, a human monoclonal antibody that targets vascular endothelial growth factor (VEGF); cetuximab, a chimeric human mouse monoclonal antibody against the epidermal growth factor receptor (EGFR), and panitumumab, a fully human antibody that targets the extracellular domain of EGFR.

Bevacizumab was approved after Goldberg et al. [37] and Hurwitz et al. [50] showed a survival benefit for the addition of bevacizumab to IFL. However, in a phase III study of 1,401 patients randomized to FOLFOX4 or XELOX with or without bevacizumab, PFS was extended in the bevacizumab population ( 9.4 vs. 8.0 months, $\mathrm{p}=$ $0.0023)$ [51], but median OS (21.9 vs. 19.9, p = 0.0769) and RR ( $47 \%$ vs. $49 \%, \mathrm{p}=0.31$ ) were similar in both arms. Furthermore, the PFS benefit was limited to the XELOX $\operatorname{arm}(9.3$ vs. 7.4 months, $\mathrm{p}=0.003$ but for FOLFOX: 9.4 vs. 8.6 months, $\mathrm{p}=0.19$ ). More patients discontinued treatment because of adverse events, including thromboembolic events and bowel perforations, in the bevacizumab containing arm (30\% vs. $21 \%)$. While angiogenesis contributes to solid-tumor development $[52,53]$, it is unclear whether bevacizumab improves outcome with better chemotherapy regimens in the first-line setting. For patients with refractory disease, the addition of bevacizumab to FOLFOX improves RR $(22.6 \%$ vs. $8.6 \%, \mathrm{p}<0.001)$, PFS (7.3 vs. 4.7 months, $\mathrm{p}<0.0001)$, and OS ( 12.9 vs. 10.8 , $\mathrm{p}=0.0011$ ) [54], and two observational studies support continuation of bevacizumab beyond progression [55, 56]. Physiological (hypertension [57]), genetic (VEGF genotype [58]) and circulating (VEFG [59-61], placentalderived growth factor [62] and VEGF receptors [63]) biomarkers have been retrospectively identified to guide patient selection but require validation in larger prospective studies before translation into the clinic [64].

The fact that approximately $80 \%$ of colorectal tumors stain positively for EGFR generated widespread interest in this pathway, resulting in two FDA-approved antiEGFR agents. Cetuximab appears to restore sensitivity to irinotecan in refractory patients by increasing RR ( $23 \%$ vs. $11 \%, \mathrm{p}=0.007)$ and prolonging PFS (4.1 vs. 1.5 months, $\mathrm{p}<0.0001)$ in combination with irinotecan compared to single agent cetuximab [65]. In the first-line setting, FOLFIRI plus cetuximab also improves RR $(46.9 \%$ vs. $38.7 \%$, $\mathrm{p}=0.005)$ and PFS (8.9vs. 8.0, p =0.036) [66]. In the refractory setting, it improves RR ( 23 vs. $11 \%, p=0.007$ ) and time 
to progression (4.1 vs. 1.5 months, $\mathrm{p}<0.0001$ ) [67]. Panitumumab plus best supportive care improves PFS over best supportive care alone in previously treated patients [68].

It was initially anticipated that the presumed targets of these agents (VEGF and EGFR) would serve as clinically useful biomarkers, in the same way that the HER2 status of a breast tumor can be used for treatment selection and prognostication $[69,70]$. However, EGFR expression measured using immunohistochemistry is poorly predictive of response to cetuximab [67, 71-73], and more accurate measurement of EGFR status using fluorescent in situ hybridization and polymerase chain reaction does not provide clinically useful information. Patients whose tumors have a low EGFR gene copy number by fluorescent in situ hybridization are less likely to respond to anti-EGFR therapies, but high EGFR gene copy number is not associated with response to anti-EGFR therapy [74, 75]. Similarly, EGFR measured using polymerase chain reaction does not predict response to cetuximab, but does correlate with survival [76]. However, the mutation status of KRAS, a gene encoding the KRAS proto-oncogene downstream effector of EGFR, has been associated with poor prognosis and nonresponse to EGFR antagonists [77-80]. In fact, panitumimab was approved in Europe for patients with MCRC with wild-type KRAS (i.e. no mutation), after a phase III study demonstrated worse survival in patients with KRAS mutant tumors (hazard ratio, $\mathrm{HR}=0.45,95 \%$ confidence interval, $\mathrm{CI}, 0.34-0.59$ ) [81], and two recent phase III studies confirm this association $[82,83]$. Similarly, the benefit for cetuximab plus FOLFIRI was greater in KRAS wild-type tumors, with significant difference in PFS $(\mathrm{HR}=0.68, \mathrm{p}=0.017)$ and RR (59\% vs. $43 \%, \mathrm{p}=0.0025)$ [84].

The single-agent activity of these antibodies encouraged investigators to combine multiple biologics with chemotherapy regimens [85]. However, the combination of these biologics proved deleterious. In a large randomized phase IIIB study of FOLFOX4/FOLFIRI plus bevacizumab + or - panitumumab, there was an increased incidence of serious adverse events ( $56 \%$ vs. $37 \%$ ), a reduced median PFS (9.0 vs. 10.5 months; HR $=1.29$; 95\% CI, $1.05-$ $1.58)$ and $\mathrm{OS}(18.6$ vs. not reached; $\mathrm{HR}=1.44 ; 95 \% \mathrm{CI}$, $1.10-1.88$ ), with two biologics versus one [86]. A study performed by the Dutch Colorectal Cancer Group randomized 716 patients to capecitabine, oxaliplatin, bevacizumab, + or - cetuximab and demonstrated a shorter PFS (9.8 vs. 10.7 months, $\mathrm{p}=0.019$ ) with the two antibodies versus one antibody [87]. Similarly, the addition of cetuximab to capecitabine, oxaliplatin and bevacizumab resulted in inferior PFS, especially in patients with mutated
KRAS who received cetuximab [88], similar to previous reports [84, 89].

KRAS is therefore a biomarker with clinical utility and oncologists are now obliged to test KRAS mutational status prior to initiating therapy with cetuximab. However, KRAS does not predict response, i.e. only $30 \%$ of MCRC patients with KRAS wild-type tumors (nonmutated) respond to cetuximab, highlighting the limitations of a single biomarker, and other complementary predictors are needed. Pathways downstream of EGFR such as PI3K/ PTEN/Akt or JAK/STAT have been investigated for biomarkers of EGFR antibody resistance [90], and BRAF status, EGFR amplification, and cytoplasmic expression of PTEN can be used to further stratify this population [91]. Additional targeted biological agents are in development for the treatment of MCRC that offer hope of further improvements in outcome for patients with MCRC [92].

\section{Surgical Resection of Hepatic Metastases and Perioperative Systemic Therapy}

Complete responses have been reported with systemic chemotherapy for patients with MCRC but long-term cure is rare with chemotherapy alone (table 1). Complete surgical resection of CLM is associated with $30-50 \%$ survival at 5 years [93-95]. Extrahepatic disease is typically considered a contradiction to hepatic resection but occasionally isolated extrahepatic metastases are resected and a $28 \% 5$-year survival has been reported even in these patients [96].

Complete resection is essential since patients who undergo incomplete resection appear to have similar outcomes to patients who are not resected [97]. Unresectable CLM can be rendered resectable by preoperative chemotherapy, and in a study of 1,104 unresectable patients made resectable by chemotherapy survival rates were $33 \%$ at 5 years and $23 \%$ at 10 years, which is almost as good as for patients who are resectable at presentation [98]. Perioperative chemotherapy is also used for patients with resectable hepatic metastases to facilitate less radical surgery, and treat micrometastases. Some claim that response to chemotherapy predicts survival [99] although others report that patients who progress but remain candidates for surgical resection have the same outcome as responders [95], suggesting that close follow-up is required so as not to miss the resection window. Postoperative systemic chemotherapy appears beneficial after complete surgical resection [100-104]. Pooled analysis of two multicenter studies supports adjuvant systemic che- 
Table 1. Clinical trials demonstrating progress in the systemic management of MCRC in the past 15 years

\begin{tabular}{|c|c|c|c|c|c|}
\hline Clinical trial & Treatment & $\begin{array}{l}\text { Median OS } \\
\text { months }\end{array}$ & $\begin{array}{l}\text { OS benefit } \\
\text { months }\end{array}$ & $\mathrm{p}$ value & $\begin{array}{l}\text { CR rate } \\
\%^{1}\end{array}$ \\
\hline $\begin{array}{l}\text { Scheithauer et al., } 1993 \\
\text { [17] }\end{array}$ & $\begin{array}{l}5-\mathrm{FU}+\mathrm{LV} \\
\mathrm{BSC}\end{array}$ & $\begin{array}{r}11 \\
5\end{array}$ & 6 & 0.006 & 0 \\
\hline $\begin{array}{l}\text { Saltz et al., } 2000 \\
{[156]}\end{array}$ & $\begin{array}{l}\text { IFL } \\
\text { bolus 5-FU }\end{array}$ & $\begin{array}{l}14.8 \\
12.6\end{array}$ & 2.2 & 0.04 & $\begin{array}{l}2.6 \\
0.8\end{array}$ \\
\hline $\begin{array}{l}\text { Kohne et al., } 2005 \\
{[33]}\end{array}$ & $\begin{array}{l}\text { inf. 5-FU/LV } \\
\text { inf. 5-FU/LV + CPT-11 }\end{array}$ & $\begin{array}{l}16.9 \\
20.1\end{array}$ & 3.2 & NS & $\begin{array}{l}3.7 \\
2.8\end{array}$ \\
\hline $\begin{array}{l}\text { Van Cutsem et al., } 2001 \\
\text { [20] }\end{array}$ & $\begin{array}{l}\text { bolus } 5 \text {-FU/LV } \\
\text { capecitabine }\end{array}$ & $\begin{array}{l}12.1 \\
13.2\end{array}$ & 1.1 & NS & $\begin{array}{l}0.7 \\
0.3\end{array}$ \\
\hline $\begin{array}{l}\text { De Gramont et al., } 2000 \\
\text { [157] }\end{array}$ & $\begin{array}{l}\text { inf./bolus 5-FU/LV } \\
\text { inf./bolus 5-FU/LV + oxaliplatin }\end{array}$ & $\begin{array}{l}14.7 \\
16.2\end{array}$ & 1.5 & NS & $\begin{array}{l}0.5 \\
1.4\end{array}$ \\
\hline $\begin{array}{l}\text { Goldberg et al., } 2004 \\
\text { [37] }\end{array}$ & $\begin{array}{l}\text { IFL } \\
\text { FOLFOX } 4\end{array}$ & $\begin{array}{l}15 \\
19.5\end{array}$ & 4.5 & 0.0001 & NR \\
\hline $\begin{array}{l}\text { Tournigand et al., } 2004 \\
\text { [45] }\end{array}$ & $\begin{array}{l}\text { inf./bolus 5-FU/LV + CPT-11 } \\
\text { FOLFOX6 }\end{array}$ & $\begin{array}{l}21.5 \\
20.6\end{array}$ & 0.9 & NS & $\begin{array}{l}3 \\
5\end{array}$ \\
\hline $\begin{array}{l}\text { Hurwitz et al., } 2004 \\
\text { [50] }\end{array}$ & $\begin{array}{l}\mathrm{IFL}+\text { placebo } \\
\mathrm{IFL}+\mathrm{Bev}\end{array}$ & $\begin{array}{l}15.6 \\
20.3\end{array}$ & 4.7 & $<0.001$ & $\begin{array}{l}2.2 \\
3.7\end{array}$ \\
\hline $\begin{array}{l}\text { Falcone et al., } 2007 \\
{[41]}\end{array}$ & $\begin{array}{l}\text { FOLFIRI } \\
\text { FOLFOXIRI }\end{array}$ & $\begin{array}{l}16.7 \\
22.6\end{array}$ & 5.9 & 0.032 & $\begin{array}{l}5 \\
7\end{array}$ \\
\hline $\begin{array}{l}\text { Cassidy et al., } 2008 \\
\text { [38] }\end{array}$ & $\begin{array}{l}\text { FOLFOX } 4 \\
\text { XELOX }\end{array}$ & $\begin{array}{l}19.6 \\
19.8\end{array}$ & 0.2 & NS & NR \\
\hline $\begin{array}{l}\text { Saltz et al., } 2008 \\
{[51]}\end{array}$ & $\begin{array}{l}\text { FOLFOX/XELOX + placebo } \\
\text { FOLFOX/XELOX + Bev }\end{array}$ & $\begin{array}{l}19.9 \\
21.3\end{array}$ & 1.4 & 0.08 & NR \\
\hline $\begin{array}{l}\text { Van Cutsem et al., } 2009 \\
\text { [158] }\end{array}$ & $\begin{array}{l}\text { FOLFIRI } \\
\text { FOLFIRI + cetuximab }\end{array}$ & $\begin{array}{l}18.6 \\
19.9\end{array}$ & 1.3 & NS & $\begin{array}{l}0.3 \\
0.5\end{array}$ \\
\hline $\begin{array}{l}\text { Hecht et al., } 2009^{2} \\
{[159]}\end{array}$ & $\begin{array}{l}\text { Chemo + Bev } \\
\text { Chemo + Bev + PMAB }\end{array}$ & $\begin{array}{l}24.5 \\
19.4\end{array}$ & 5.1 & NR & $\begin{array}{l}0.4 \\
0\end{array}$ \\
\hline
\end{tabular}

$\mathrm{CR}=$ Complete response; $\mathrm{BSC}=$ best supportive care; inf. = infusion; $\mathrm{Bev}=$ bevacizumab; $\mathrm{PMAB}=$ panitumumab; $\mathrm{NR}=$ not reported; NS = not statistically significant.

${ }^{1}$ Complete response to chemotherapy alone.

2 Trial closed prematurely due to inferior outcome in panitumumab arm.

motherapy over surgery alone, with a trend towards an improvement in median PFS ( $\mathrm{p}=0.059)$, and in a multivariate analysis adjuvant chemotherapy was significantly associated with a better OS ( $\mathrm{p}=0.046)$ [104-107]; nonetheless, level 1 evidence is lacking and clinical trials addressing this question are needed.

No biomarker reliably predicts outcome after treatment of CLM although a number of prognostic scoring systems have been developed that are useful for patient selection for resection and for stratification in clinical trials [107-111].

Treatment of Metastatic Colorectal Cancer

\section{Hepatic Arterial Infusion Chemotherapy: Pushing the Boundary of Hepatic Resection}

Direct infusion of the liver is possible as liver neoplasms are fed primarily by the hepatic artery whereas the portal vein supplies the normal liver [112]. Floxuridine (FUDR), a pyrimidine antimetabolite, is used in preference to 5-FU because of its short half-life and high rate of hepatic extraction (90\%), leading to a 400 -fold estimated increased exposure [113]. Direct infusion of chemotherapy into the hepatic artery exposes the tumor to higher

Oncology 2010;78:237-248 


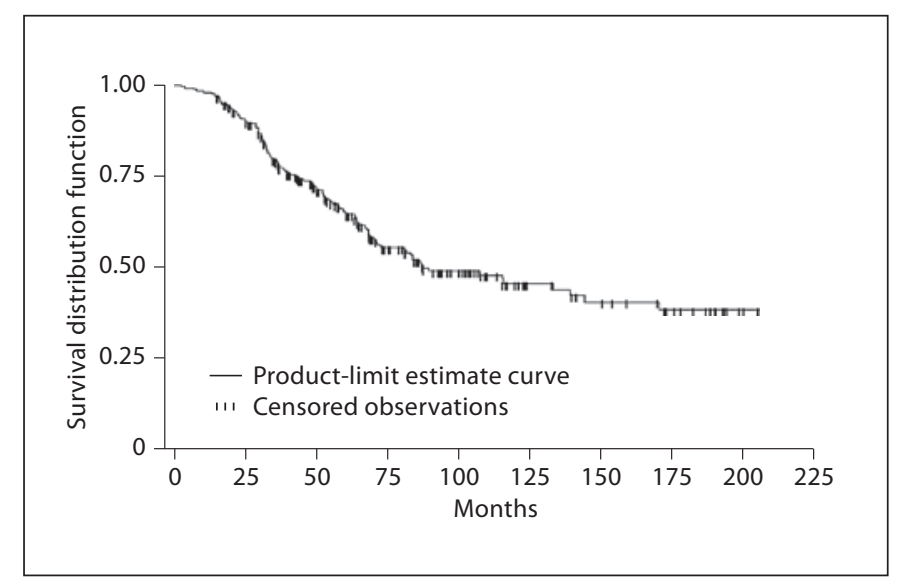

Fig. 1. OS for 218 patients on adjuvant HAI studies at Memorial Sloan-Kettering Cancer Center.

drug concentrations with minimal systemic toxicity. The development of a totally implantable pump facilitated the development of hepatic artery infusion (HAI) [114]. The approach has been criticized because of its associated hepatic toxicity, but hepatic toxicity, the major complication, can be minimized with close monitoring of patients, careful catheter placement resulting in less displacement and occlusion problems [115], and the addition of dexamethasone to FUDR which reduces the rates of biliary toxicity [116].

A recent meta-analysis reported a significantly better response rate for HAI chemotherapy $(42.9 \%$ vs. $18.4 \%$, $\mathrm{p}<0.0001)$ compared with systemic 5-FU-based therapy [117], and a cooperative group study demonstrated improved OS favoring HAI (24.4 vs. 20 months, $\mathrm{p}=0.0039)$ [118]. The former study concluded that fluoropyrimidine-based HAI should not be used alone in the first-line treatment of colorectal cancer [117], and HAI has more recently been combined with systemic therapy in a number of single-institution studies with impressive results. A median survival of 41 months was reported in one study that combined HAI with systemic oxaliplatin and irinotecan in 49 patients with unresectable liver metastases [119]. The RR in this study was $92 \%$. Forty-nine percent of these patients were able to undergo resection though clearly unresectable at initiation of therapy $[119$, 120].

HAI can be administered in the postoperative setting with increased survival. In a randomized study of HAI + systemic therapy versus systemic 5-FU/LV alone, the 2 -year survival (the endpoint of the study) was $86 \%$ versus $72 \%(\mathrm{p}=0.03)$ in HAI + systemic versus systemic

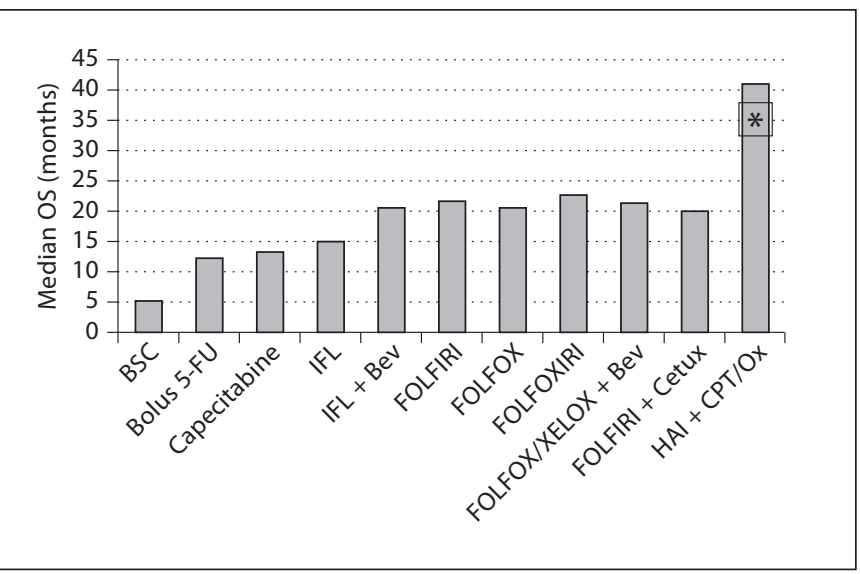

Fig. 2. Median OS and complete response (CRR) with systemic chemotherapy regimens for metastatic colorectal cancer. BSC = Best supportive care; $\mathrm{Bev}=$ bevacizumab; Cetux = cetuximab; $\mathrm{CPT}=$ irinotecan; $\mathrm{Ox}=$ oxaliplatin. ${ }^{*}$ is the $\mathrm{OS}$ observed in a phase II study whereas other results in this figure are from phase III studies.

groups, respectively [121]. In a later report with a median follow-up of 10.3 years, the 10 -year survival was $41.1 \%$ versus $27.7 \%$, for the 2 groups, respectively [122]. Figure 1 illustrates the collective median survival from 4 studies at Memorial Sloan-Kettering Cancer Center evaluating HAI and systemic therapy after resection in 218 patients. With a median follow-up of 69 months the 5 -year survival is close to $70 \%$ and 10 -year survival approximately $50 \%$. Close cooperation with surgeons to remove small recurrences and further chemotherapy if necessary can increase long-term survival. It appears that the hepatic parenchyma is particularly receptive to circulating colorectal cancer cells. It is unclear whether extrahepatic metastases are initiated at the same time as the liver lesions, or whether these hepatic metastases go on to seed extrahepatic sites, but cells may require additional mutations to survive in organs other than the liver. A hypothesis whereby the liver acts as 'gatekeeper' might explain the success of liver resection and HAI treatments, emphasizing the importance of further developing this modality using agents other than FUDR.

\section{Radiofrequency Ablation (RFA) for the Treatment of Unresectable or Recurrent Hepatic Metastases}

RFA offers an opportunity to eliminate residual metastases that are small in size or few in number when an R0 resection is not possible despite optimal systemic che- 
motherapy and surgical expertise. RFA is a complementary option to surgery and chemotherapy for individuals with CLM and limited tumor burden ( $\leq 3$ CLM, and lesion size $\leq 3 \mathrm{~cm}$ ) or in patients with comorbidities, or poor hepatic reserve [123]. Despite its widespread use, there are no randomized data supporting RFA, and the clinical benefit of this treatment is unclear. A recent review of RFA by the American Society of Clinical Oncology concluded that 'there is a compelling need for more research to determine the efficacy and utility of RFA to increase local recurrence-free, progression-free, and disease-free survival as well as OS for patients with CLM' [124]. Two studies that attempted to investigate its benefit in a randomized phase III setting were closed early due to poor accrual; however, 13 clinical series and $8 \mathrm{com}$ parative studies demonstrate long-term OS after RFA treatment [125-143]. The heterogeneous nature of these studies prevented a meaningful meta-analysis, but a recent systematic analysis of 1,578 patients with 3,655 RFAtreated CLM concluded that RFA can be a useful adjunct to both chemotherapy and surgery, resulting in a complete response or R0 resection, respectively, by eradication of residual lesions [123]. Studies comparing RFA with resection are often biased in favor of resection as hepatectomy likely removes undetected metastases and patients considered for RFA are usually more advanced. Nonetheless, long-term survival has been reported with 5 -year survival up to $18 \%$ from the time of RFA [130]. The management of MCRC requires an individualized approach and RFA has a role to play in the coordinated, multidisciplinary care of patients.

\section{The Success of and Future Hope for Personalized Therapy}

The data presented here illustrate that with timely intervention coordinated by a multidisciplinary team, a greater number, albeit select minority, of patients with MCRC can be cured. The use of new, effective systemic and HAI chemotherapies with improved surgical techniques and RFA has expanded the definition of resectability. This success is in part due to the appropriate selection of patients for specific intervention using predominantly clinically criteria. Molecular characterization of patients and their disease may identify biomarkers to further refine treatment selection, resulting in a personalized approach for individual patients. A greater understanding of the biology of MCRC has also contributed to this progress, and ongoing developments continue to provide insight into colorectal cancer pathogenesis that will hopefully result in further novel therapeutic approaches.

Recent advances including The HapMap project, The Human Genome project and the introduction of highthroughput genotyping have facilitated the scrutiny of DNA at a new level. Large genome-wide association studies (GWAS) have been performed, and to date 7 GWAS in colorectal cancer have identified 10 risk loci associated with a risk of developing colorectal cancer [144-150]. These genetic markers may direct screening and preventive therapy approaches, but may also identify unappreciated disease biology. No GWAS has yet investigated genetic variants associated with the development of MCRC, but it is possible that germ line markers exist that will serve the dual function of identifying individuals likely to develop metastases and elucidation of disease biology. Five of the 10 loci already reported are associated with the transforming growth factor- $\beta$ signaling pathway, confirming the importance of this pathway in colorectal cancer carcinogenesis, and illustrating how this technology can improve our understanding of disease biology. Other genome-wide profiling studies have identified regulators of gene expression termed microRNAs that are deregulated in colorectal cancer. These small interfering RNAs may further enhance our understanding of colorectal cancer pathogenesis and provide clinically useful biomarkers and therapeutic targets [151-153]. Circulating tumor cells with metastatic potential have also been identified as prognostic markers in patients with colorectal cancer and are another biomarker under investigation [154]. These cells may contain molecular alterations that mirror cells within metastatic deposits and as such may reveal important somatic predictors of response to therapy [155]. To be clinically useful, molecular biomarkers will have to improve upon the predictive power of clinical characteristics presently used to guide treatment decisions, but recent advances suggest that molecular determinants may increasingly factor in the multidisciplinary management of patients with MCRC.

\section{Conclusion}

Advances in the systemic management of MCRC are reflected by the improved median survival times in recent phase III trials. Aggressive multidisciplinary management of CLM results in up to a $40 \%$ cure rate for a select minority of patients with MCRC. Improved RR with novel systemic regimens and targeted local ap- 
proaches such as HAI have expanded the cohort of patients that can now be approached with curative intent. KRAS mutation testing identifies a group of patients that should not receive cetuximab, but biomarkers are needed which would enable selection of a subset of patients likely to respond. Recent technological developments have provided us with the tools to scrutinize DNA and RNA, and have the potential to discover clinically useful biomarkers. This goal of personalized medicine may facilitate a more cost-effective and appropriate use of the large number of currently available therapies, and may also identify new biology for the further development of individualized treatment.

\section{References}

1 Paget S: The distribution of secondary growths in cancer of the breast. Lancet 1889; 133:571-573.

2 Paku S, Dome B, Toth R, Timar J: Organspecificity of the extravasation process: an ultrastructural study. Clin Exp Metastasis 2000;18:481-492.

$\checkmark 3$ Lalor PF, Lai WK, Curbishley SM, Shetty S, Adams DH: Human hepatic sinusoidal endothelial cells can be distinguished by expression of phenotypic markers related to their specialised functions in vivo. World J Gastroenterol 2006;12:5429-5439.

4 Hart IR, Fidler IJ: Role of organ selectivity in the determination of metastatic patterns of B16 melanoma. Cancer Res 1980;40:22812287.

5 Fidler IJ, Poste G: The 'seed and soil' hypothesis revisited. Lancet Oncol 2008;9:808.

6 Nguyen DX, Bos PD, Massague J: Metastasis: from dissemination to organ-specific colonization. Nat Rev Cancer 2009;9:274-284

$\checkmark 7$ Chambers AF, Groom AC, MacDonald IC: Dissemination and growth of cancer cells in metastatic sites. Nat Rev Cancer 2002;2:563572 .

$>8$ Fearon ER, Vogelstein B: A genetic model for colorectal tumorigenesis. Cell 1990;61:759767.

-9 Kinzler KW, Vogelstein B: Lessons from hereditary colorectal cancer. Cell 1996;87:159170 .

-10 Vogelstein B, Fearon ER, Hamilton SR, et al: Genetic alterations during colorectal-tumor development. N Engl J Med 1988;319:525532 .

-11 Samuels Y, Wang Z, Bardelli A, et al: High frequency of mutations of the PIK3CA gene in human cancers. Science 2004;304:554.

- 12 Baker SJ, Fearon ER, Nigro JM, et al: Chromosome 17 deletions and p53 gene mutations in colorectal carcinomas. Science 1989; 244:217-221.

-13 Markowitz S, Wang J, Myeroff L, et al: Inactivation of the type II TGF- $\beta$ receptor in colon cancer cells with microsatellite instability. Science 1995;268:1336-1338.
14 Heidelberger C, Chaudhuri NK, Danneberg $\mathrm{P}$, et al: Fluorinated pyrimidines, a new class of tumour-inhibitory compounds. Nature 1957;179:663-666

15 Sullivan RD, Norcross JW, Watkins E Jr: Chemotherapy of metastatic liver cancer by prolonged hepatic-artery infusion. N Engl J Med 1964;270:321-327.

16 Zhang ZG, Harstrick A, Rustum YM: Modulation of fluoropyrimidines: role of dose and schedule of leucovorin administration. Semin Oncol 1992;19:10-15.

-17 Scheithauer W, Rosen H, Kornek GV, Sebesta C, Depisch D: Randomised comparison of combination chemotherapy plus supportive care with supportive care alone in patients with metastatic colorectal cancer. BMJ 1993 ; 306:752-755.

18 Expectancy or primary chemotherapy in patients with advanced asymptomatic colorectal cancer: a randomized trial. Nordic Gastrointestinal Tumor Adjuvant Therapy Group. J Clin Oncol 1992;10:904-911.

19 de Gramont A, Bosset JF, Milan C, et al: Randomized trial comparing monthly low-dose leucovorin and fluorouracil bolus with bimonthly high-dose leucovorin and fluorouracil bolus plus continuous infusion for advanced colorectalcancer:a French intergroup study. J Clin Oncol 1997;15:808-815.

20 Van Cutsem E, Twelves C, Cassidy J, et al: Oral capecitabine compared with intravenous fluorouracil plus leucovorin in patients with metastatic colorectal cancer: results of a large phase III study. J Clin Oncol 2001;19: 4097-4106.

21 Cassidy J, Twelves C, Van Cutsem E, et al: First-line oral capecitabine therapy in metastatic colorectal cancer: a favorable safety profile compared with intravenous 5-fluorouracil/leucovorin. Ann Oncol 2002;13:566575.

22 Twelves C, Gollins S, Grieve R, Samuel L: A randomised cross-over trial comparing patient preference for oral capecitabine and 5 -fluorouracil/leucovorin regimens in patients with advanced colorectal cancer. Ann Oncol 2006; 17:239-245.
23 Mayer RJ: Should capecitabine replace infusional fluorouracil and leucovorin when combined with oxaliplatin in metastatic colorectal cancer? J Clin Oncol 2007;25: 4165-4167.

24 Shirasaka T: Development history and concept of an oral anticancer agent S-1 (TS-1): its clinical usefulness and future vistas. Jpn J Clin Oncol 2009;39:2-15.

25 Ezzeldin HH, Diasio RB: Predicting fluorouracil toxicity: can we finally do it? J Clin Oncol 2008;26:2080-2082.

26 Haller DG, Cassidy J, Clarke SJ, et al: Potential regional differences for the tolerability profiles of fluoropyrimidines. J Clin Oncol 2008;26:2118-2123.

27 Schwab M, Zanger UM, Marx C, et al: Role of genetic and nongenetic factors for fluorouracil treatment-related severe toxicity: a prospective clinical trial by the German 5-FU Toxicity Study Group. J Clin Oncol 2008;26:2131-2138.

$>28$ Longley DB, Allen WL, Johnston PG: Drug resistance, predictive markers and pharmacogenomics in colorectal cancer. Biochim Biophys Acta 2006;1766:184-196.

-29 Tokunaga Y, Hosogi H, Hoppou T, Nakagami M, Tokuka A, Ohsumi K: Prognostic value of thymidine phosphorylase/platelet-derived endothelial cell growth factor in advanced colorectal cancer after surgery: evaluation with a new monoclonal antibody. Surgery 2002;131:541-547.

30 Salonga D, Danenberg KD, Johnson M, et al: Colorectal tumors responding to 5-fluorouracil have low gene expression levels of dihydropyrimidine dehydrogenase, thymidylate synthase, and thymidine phosphorylase. Clin Cancer Res 2000;6:1322-1327.

-31 Metzger R, Danenberg K, Leichman CG, et al: High basal level gene expression of thymidine phosphorylase (platelet-derived endothelial cell growth factor) in colorectal tumors is associated with nonresponse to 5-fluorouracil. Clin Cancer Res 1998;4: 2371-2376

\$2 Matsuyama R, Togo S, Shimizu D, et al: Predicting 5-fluorouracil chemosensitivity of liver metastases from colorectal cancer using primary tumor specimens: three-gene expression model predicts clinical response. Int J Cancer 2006;119:406-413. 
33 Kohne CH, van Cutsem E, Wils J, et al: Phase III study of weekly high-dose infusional fluorouracil plus folinic acid with or without irinotecan in patients with metastatic colorectal cancer: European Organisation for Research and Treatment of Cancer Gastrointestinal Group Study 40986. J Clin Oncol 2005;23:4856-4865.

34 Beutler E: Targeted disruption of the HFE gene. Proc Natl Acad Sci USA 1998;95:20332034.

- 35 Innocenti F, Undevia SD, Iyer L, et al: Genetic variants in the UDP-glucuronosyltransferase $1 \mathrm{~A} 1$ gene predict the risk of severe neutropenia of irinotecan. J Clin Oncol 2004;22:1382-1388.

- 36 Cecchin E, Innocenti F, D’Andrea M, et al: Predictive role of the UGT1A1, UGT1A7, and UGT1A9 genetic variants and their haplotypes on the outcome of metastatic colorectal cancer patients treated with fluorouracil, leucovorin, and irinotecan. J Clin Oncol 2009;27:2457-2465.

- 37 Goldberg RM, Sargent DJ, Morton RF, et al: A randomized controlled trial of fluorouracil plus leucovorin, irinotecan, and oxaliplatin combinations in patients with previously untreated metastatic colorectal cancer. J Clin Oncol 2004;22:23-30.

38 Cassidy J, Clarke S, Diaz-Rubio E, et al: Randomized phase III study of capecitabine plus oxaliplatin compared with fluorouracil/folinic acid plus oxaliplatin as first-line therapy for metastatic colorectal cancer. J Clin Oncol 2008;26:2006-2012.

- 39 Fuchs CS, Marshall J, Mitchell E, et al: Randomized, controlled trial of irinotecan plus infusional, bolus, or oral fluoropyrimidines in first-line treatment of metastatic colorectal cancer: results from the BICC-C Study. J Clin Oncol 2007;25:4779-4786.

-40 Grothey A, Sargent D, Goldberg RM, Schmoll HJ: Survival of patients with advanced colorectal cancer improves with the availability of fluorouracil-leucovorin, irinotecan, and oxaliplatin in the course of treatment. J Clin Oncol 2004;22:1209-1214.

41 Falcone A, Ricci S, Brunetti I, et al: Phase III trial of infusional fluorouracil, leucovorin, oxaliplatin, and irinotecan (FOLFOXIRI) compared with infusional fluorouracil, leucovorin, and irinotecan (FOLFIRI) as firstline treatment for metastatic colorectal cancer: the Gruppo Oncologico Nord Ovest. J Clin Oncol 2007;25:1670-1676.

-42 Seymour MT, Maughan TS, Ledermann JA, et al: Different strategies of sequential and combination chemotherapy for patients with poor prognosis advanced colorectal cancer (MRC FOCUS): a randomised controlled trial. Lancet 2007;370:143-152.

-43 Koopman M, Antonini NF, Douma J, et al: Sequential versus combination chemotherapy with capecitabine, irinotecan, and oxaliplatin in advanced colorectal cancer (CAIRO): a phase III randomised controlled trial. Lancet 2007;370:135-142.
44 O’Neil BH, Goldberg RM: Innovations in chemotherapy for metastatic colorectal cancer: an update of recent clinical trials. Oncologist 2008;13:1074-1083.

45 Tournigand C, Andre T, Achille E, et al: FOLFIRI followed by FOLFOX6 or the reverse sequence in advanced colorectal cancer: a randomized GERCOR study. J Clin Oncol 2004;22:229-237.

46 Colucci G, Gebbia V, Paoletti G, et al: Phase III randomized trial of FOLFIRI versus FOLFOX4 in the treatment of advanced colorectal cancer: a multicenter study of the Gruppo Oncologico Dell'Italia Meridionale. J Clin Oncol 2005;23:4866-4875.

47 Tournigand C, Cervantes A, Figer A, et al: OPTIMOX1: a randomized study of FOLFOX4 or FOLFOX7 with oxaliplatin in a stop-and-go fashion in advanced colorectal cancer - a GERCOR study. J Clin Oncol 2006;24:394-400.

48 Maindrault-Goebel F, Lledo G, Chibaudel B, et al: Final results of OPTIMOX2, a large randomized phase II study of maintenance therapy or chemotherapy-free intervals (CFI) after FOLFOX in patients with metastatic colorectal cancer (MRC): a GERCOR study. ASCO Annual Meeting Proceedings Part I. J Clin Oncol 2007;25(No 18S, suppl):4013.

49 Labianca R FI, Cortesi E, et al: Alternating versus continuous 'FOLFIRI' in advanced colorectal cancer (ACC): a randomized 'GISCAD' trial. ASCO Annu Meet Proc, pt 1. J Clin Oncol 2006;24(No 18S, suppl):3505.

50 Hurwitz H, Fehrenbacher L, Novotny W, et al: Bevacizumab plus irinotecan, fluorouracil, and leucovorin for metastatic colorectal cancer. N Engl J Med 2004;350:2335-2342.

51 Saltz LB, Clarke S, Diaz-Rubio E, et al: Bevacizumab in combination with oxaliplatinbased chemotherapy as first-line therapy in metastatic colorectal cancer: a randomized phase III study. J Clin Oncol 2008;26:20132019.

52 Carmeliet P, Jain RK: Angiogenesis in cancer and other diseases. Nature 2000;407:249257.

53 Folkman J: Tumor angiogenesis: therapeutic implications. N Engl J Med 1971;285:11821186.

54 Giantonio BJ, Catalano PJ, Meropol NJ, et al: Bevacizumab in combination with oxaliplatin, fluorouracil, and leucovorin (FOLFOX4) for previously treated metastatic colorectal cancer: results from the Eastern Cooperative Oncology Group Study E3200. J Clin Oncol 2007;25:1539-1544.

55 Grothey A SM, Hedrick E, Purdie D, Yi J, Dong W, Kozloff M; and the BRiTE Study Investigators: Association between exposure to bevacizumab (BV) beyond first progression (BBP) and overall survival (OS) in patients (pts) with metastatic colorectal cancer (mCRC): results from a large observational study (BRiTE). ASCO Annual Meeting Proceedings Part I. J Clin Oncol 2007;25(No 18S, suppl):4036.
56 Van Cutsem E, Rivera F, Berry S, et al: Safety and efficacy of first-line bevacizumab with FOLFOX, XELOX, FOLFIRI and fluoropyrimidines in metastatic colorectal cancer: the BEAT study. Ann Oncol 2009;20:18421847. Epub 2009 Apr 30

57 Rini BI SJ, Fruehauf JP, et al: Association of diastolic blood pressure (dBP) $>90 \mathrm{mmHg}$ with overall survival (OS) in patients treated with axitinib (AG-013736). J Clin Oncol 2008;26(suppl):3543.

58 Schneider BP, Wang M, Radovich M, et al: Association of vascular endothelial growth factor and vascular endothelial growth factor receptor-2 genetic polymorphisms with outcome in a trial of paclitaxel compared with paclitaxel plus bevacizumab in advanced breast cancer: ECOG 2100. J Clin Oncol 2008;26:4672-4678.

-59 Burstein HJ, Chen YH, Parker LM, et al: VEGF as a marker for outcome among advanced breast cancer patients receiving anti-VEGF therapy with bevacizumab and vinorelbine chemotherapy. Clin Cancer Res 2008; 14:7871-7877.

60 Jubb AM, Hurwitz HI, Bai W, et al: Impact of vascular endothelial growth factor-A expression, thrombospondin-2 expression, and microvessel density on the treatment effect of bevacizumab in metastatic colorectal cancer. J Clin Oncol 2006;24:217-227.

61 Dowlati A, Gray R, Sandler AB, Schiller JH, Johnson DH: Cell adhesion molecules, vascular endothelial growth factor, and basic fibroblast growth factor in patients with non-small cell lung cancer treated with chemotherapy with or without bevacizumab an Eastern Cooperative Oncology Group Study. Clin Cancer Res 2008;14:1407-1412.

62 Rini BI, Michaelson MD, Rosenberg JE, et al: Antitumor activity and biomarker analysis of sunitinib in patients with bevacizumabrefractory metastatic renal cell carcinoma. J Clin Oncol 2008:26:3743-3748.

63 Willett CG, Duda DG, di Tomaso E, et al: Efficacy, safety, and biomarkers of neoadjuvant bevacizumab, radiation therapy, and fluorouracil in rectal cancer: a multidisciplinary phase II study. J Clin Oncol 2009;27:30203026

64 Jain RK, Duda DG, Willett CG, et al: Biomarkers of response and resistance to antiangiogenic therapy. Nat Rev Clin Oncol 2009;6:327-338.

65 Cunningham D, Humblet Y, Siena S, et al: Cetuximab monotherapy and cetuximab plus irinotecan in irinotecan-refractory metastatic colorectal cancer. N Engl J Med 2004;351:337-345. 
66 Van Cutsem E NM, Lang I, Cascinu S, Shchepotin I, Maurel J, Rougier P, Cunningham D, Nippgen J, Köhne C: Randomized phase III study of irinotecan and 5-FU/FA with or without cetuximab in the first-line treatment of patients with metastatic colorectal cancer (mCRC): the CRYSTAL trial. ASCO Annual Meeting Proceedings Part I. J Clin Oncol 2007;25(No 18S, suppl):4000.

-67 Saltz LB, Meropol NJ, Loehrer PJ Sr, Needle MN, Kopit J, Mayer RJ: Phase II trial of cetuximab in patients with refractory colorectal cancer that expresses the epidermal growth factor receptor. J Clin Oncol 2004;22: 1201-1208.

68 Van Cutsem E, Peeters M, Siena S, et al: Open-label phase III trial of panitumumab plus best supportive care compared with best supportive care alone in patients with chemotherapy-refractory metastatic colorectal cancer. J Clin Oncol 2007;25:1658-1664.

-69 Hudis CA: Trastuzumab - mechanism of action and use in clinical practice. $\mathrm{N}$ Engl $\mathrm{J}$ Med 2007;357:39-51.

-70 Cameron DA, Stein S: Drug insight: intracellular inhibitors of HER2 - clinical development of lapatinib in breast cancer. Nat Clin Pract Oncol 2008;5:512-520.

-71 Chung KY, Shia J, Kemeny NE, et al: Cetuximab shows activity in colorectal cancer patients with tumors that do not express the epidermal growth factor receptor by immunohistochemistry. J Clin Oncol 2005;23: 1803-1810.

-72 Penault-Llorca F, Cayre A, Arnould L, et al: Is there an immunohistochemical technique definitively valid in epidermal growth factor receptor assessment? Oncol Rep 2006;16: 1173-1179.

-73 Francoual M, Etienne-Grimaldi MC, Formento JL, et al: EGFR in colorectal cancer: more than a simple receptor. Ann Oncol 2006;17:962-967.

74 Lievre A, Bachet JB, Le Corre D, et al: KRAS mutation status is predictive of response to cetuximab therapy in colorectal cancer. Cancer Res 2006;66:3992-3995.

- 75 Moroni M, Veronese S, Benvenuti S, et al: Gene copy number for epidermal growth factor receptor (EGFR) and clinical response to anti-EGFR treatment in colorectal cancer: a cohort study. Lancet Oncol 2005;6:279286.

-76 Lenz HJ, Van Cutsem E, Khambata-Ford S, et al: Multicenter phase II and translational study of cetuximab in metastatic colorectal carcinoma refractory to irinotecan, oxaliplatin, and fluoropyrimidines. J Clin Oncol 2006;24:4914-4921.

-77 De Roock W, Piessevaux H, De Schutter J, et al: KRAS wild-type state predicts survival and is associated to early radiological response in metastatic colorectal cancer treated with cetuximab. Ann Oncol 2008; 19:508515.
78 Di Fiore F, Blanchard F, Charbonnier F, et al: Clinical relevance of KRAS mutation detection in metastatic colorectal cancer treated by cetuximab plus chemotherapy. Br J Cancer 2007;96:1166-1169.

79 Frattini M, Saletti P, Romagnani E, et al: PTEN loss of expression predicts cetuximab efficacy in metastatic colorectal cancer patients. Br J Cancer 2007;97:1139-1145.

80 Khambata-Ford S, Garrett CR, Meropol NJ, et al: Expression of epiregulin and amphiregulin and K-ras mutation status predict disease control in metastatic colorectal cancer patients treated with cetuximab. J Clin Oncol 2007;25:3230-3237.

81 Amado RG, Wolf M, Peeters M, et al: Wildtype KRAS is required for panitumumab efficacy in patients with metastatic colorectal cancer. J Clin Oncol 2008;26:1626-1634.

82 Douillard J, Siena S, Cassidy J, et al: Randomized phase 3 study of panitumumab with FOLFOX4 compared to FOLFOX4 alone as 1st-line treatment (Tx) for metastatic colorectal cancer (mCRC): the PRIME trial; in ESMO 2009, Berlin, 2009.

83 Peeters MPT, Hotko Y, et al: Randomized phase 3 study of panitumumab with FOLFIRI versus FOLFIRI alone as second-line treatment (Tx) in patients (pts) with metastatic colorectal cancer (mCRC); in ESMO 2009, Berlin, 2009.

84 Van Cutsem ELI, D’haens G, Moiseyenko V, Zaluski J, Folprecht G, Tejpar S, Kisker O, Stroh C, Rougier P: KRAS status and efficacy in the first-line treatment of patients with metastatic colorectal cancer (mCRC) treated with FOLFIRI with or without cetuximab: the CRYSTAL experience. J Clin Oncol 2008; 26:(May 20 suppl; abstr 2).

85 Saltz LB, Lenz HJ, Kindler HL, et al: Randomized phase II trial of cetuximab, bevacizumab, and irinotecan compared with cetuximab and bevacizumab alone in irinotecan-refractory colorectal cancer: the BOND-2 study. J Clin Oncol 2007;25:45574561.

86 Hecht JR, Mitchell E, Chidiac T, Scroggin C, Hagenstad C, Spigel D, Marshall J, Cohn A, Shahin S, Griffin T: An updated analysis of safety and efficacy of oxaliplatin (OX)/bevacizumab (BEV) +/- panitumumab (PMAB) for first-line treatment $(\mathrm{Tx})$ of metastatic colorectal cancer (mCRC) from a randomized, controlled trial (PACCE). Proc Am Soc Clin Oncol (Gastrointestinal Symposium) 2008:abstract 273

87 Punt CJ, Tol J, Rodenburg CJ, Cats A, Creemers G, Schrama JG, Erdkamp FL, Vos A, Mol L, Antonini NF: Randomized phase III study of capecitabine, oxaliplatin, and bevacizum$\mathrm{ab}$ with or without cetuximab in advanced colorectal cancer (ACC), the CAIRO2 study of the Dutch Colorectal Cancer Group (DCCG). J Clin Oncol 2008;26:(May 20 suppl; abstr. LBA 4011)
88 Tol J, Koopman M, Cats A, et al: Chemotherapy, bevacizumab, and cetuximab in metastatic colorectal cancer. N Engl J Med 2009; 360:563-572.

-89 Bokemeyer C, Bondarenko I, Makhson A, et al: Fluorouracil, leucovorin, and oxaliplatin with and without cetuximab in the first-line treatment of metastatic colorectal cancer. J Clin Oncol 2009;27:663-671.

-90 Siena S, Sartore-Bianchi A, Di Nicolantonio F, Balfour J, Bardelli A: Biomarkers predicting clinical outcome of epidermal growth factor receptor-targeted therapy in metastatic colorectal cancer. J Natl Cancer Inst 2009; 101:1308-1324.

-91 Laurent-Puig P, Cayre A, Manceau G, et al: Analysis of PTEN, BRAF, and EGFR status in determining benefit from cetuximab therapy in wild-type KRAS metastatic colon cancer. J Clin Oncol 2009;27:5924-5930.

$\checkmark 92$ Kohne CH, Lenz HJ: Chemotherapy with targeted agents for the treatment of metastatic colorectal cancer. Oncologist 2009; 14: 478-488.

$\$ 93$ Choti MA, Sitzmann JV, Tiburi MF, et al: Trends in long-term survival following liver resection for hepatic colorectal metastases. Ann Surg 2002;235:759-766.

94 Abdalla EK, Adam R, Bilchik AJ, Jaeck D, Vauthey JN, Mahvi D: Improving resectability of hepatic colorectal metastases: expert consensus statement. Ann Surg Oncol 2006; 13:1271-1280.

95 Gallagher DJ, Zheng J, Capanu M, et al: Response to neoadjuvant chemotherapy does not predict overall survival for patients with synchronous colorectal hepatic metastases. Ann Surg Oncol 2009;16:1844-1851.

96 Nordlinger B, Vaillant JC, Guiguet M, et al: Survival benefit of repeat liver resections for recurrent colorectal metastases: 143 cases. Association Française de Chirurgie. J Clin Oncol 1994;12:1491-1496.

-97 Scheele J, Stangl R, Altendorf-Hofmann A: Hepatic metastases from colorectal carcinoma: impact of surgical resection on the natural history. Br J Surg 1990;77:1241-1246.

98 Adam R, Delvart V, Pascal G, et al: Rescue surgery for unresectable colorectal liver metastases downstaged by chemotherapy: a model to predict long-term survival. Ann Surg 2004;240:644-657; discussion 57-58.

99 Adam R, Pascal G, Castaing D, et al: Tumor progression while on chemotherapy: a contraindication to liver resection for multiple colorectal metastases? Ann Surg 2004;240: 1052-1061; discussion 61-64. 
100 Nordlinger BSH, Collette L, et al: Final results of the EORTC Intergroup randomized phase III study 40983 (EPOC) evaluating the benefit of peri-operative FOLFOX4 chemotherapy for patients with potentially resectable colorectal cancer liver metastases. ASCO Annual Meeting Proceedings Part I. J Clin Oncol 2007;25(No 18S, suppl): LBA5.

101 Portier G, Elias D, Bouche O, et al: Multicenter randomized trial of adjuvant fluorouracil and folinic acid compared with surgery alone after resection of colorectal liver metastases: FFCD ACHBTH AURC 9002 trial. J Clin Oncol 2006;24:4976-4982.

102 Parks R, Gonen M, Kemeny N, et al: Adjuvant chemotherapy improves survival after resection of hepatic colorectal metastases: analysis of data from two continents. J Am Coll Surg 2007;204:753-761; discussion 6163.

103 Tanaka K, Shimada H, Ueda M, Matsuo K, Endo I, Togo S: Role of hepatectomy in treating multiple bilobar colorectal cancer metastases. Surgery 2008;143:259-270.

104 Wang X, Hershman DL, Abrams JA, et al: Predictors of survival after hepatic resection among patients with colorectal liver metastasis. Br J Cancer 2007;97:1606-1612.

105 Mitry E, Fields AL, Bleiberg H, et al: Adjuvant chemotherapy after potentially curative resection of metastases from colorectal cancer: a pooled analysis of two randomized trials. J Clin Oncol 2008;26:49064911.

106 Petrelli NJ: Perioperative or adjuvant therapy for resectable colorectal hepatic metastases. J Clin Oncol 2008;26:4862-4863.

- 107 Iwatsuki S, Dvorchik I, Madariaga JR, et al: Hepatic resection for metastatic colorectal adenocarcinoma: a proposal of a prognostic scoring system. J Am Coll Surg 1999;189: 291-299.

108 Nordlinger B, Guiguet M, Vaillant JC, et al: Surgical resection of colorectal carcinoma metastases to the liver. A prognostic scoring system to improve case selection, based on 1,568 patients. Association Française de Chirurgie. Cancer 1996;77:1254-1262.

-109 Fong Y, Fortner J, Sun RL, Brennan MF, Blumgart LH: Clinical score for predicting recurrence after hepatic resection for metastatic colorectal cancer: analysis of 1,001 consecutive cases. Ann Surg 1999;230:309318; discussion 18-21.

110 Lise M, Bacchetti S, Da Pian P, Nitti D, Pilati P: Patterns of recurrence after resection of colorectal liver metastases: prediction by models of outcome analysis. World J Surg 2001;25:638-644.

-111 Ueno H, Mochizuki H, Hashiguchi Y, Hase K: Prognostic determinants of patients with lateral nodal involvement by rectal cancer. Ann Surg 2001;234:190-197.

- 112 Breedis C, Young G: The blood supply of neoplasms in the liver. Am J Pathol 1954;30: 969-977.
113 Ensminger WD, Rosowsky A, Raso V, et al: A clinical-pharmacological evaluation of hepatic arterial infusions of 5-fluoro-2'deoxyuridine and 5-fluorouracil. Cancer Res 1978;38:3784-3792.

114 Ensminger W, Niederhuber J, Dakhil S, Thrall J, Wheeler R: Totally implanted drug delivery system for hepatic arterial chemotherapy. Cancer Treat Rep 1981;65:393400.

115 Allen PJ, Nissan A, Picon AI, et al: Technical complications and durability of hepatic artery infusion pumps for unresectable colorectal liver metastases: an institutional experience of 544 consecutive cases. J Am Coll Surg 2005;201:57-65.

116 Kemeny N, Seiter K, Niedzwiecki D, et al: A randomized trial of intrahepatic infusion of fluorodeoxyuridine with dexamethasone versus fluorodeoxyuridine alone in the treatment of metastatic colorectal cancer. Cancer 1992;69:327-334.

117 Mocellin S, Pilati P, Lise M, Nitti D: Metaanalysis of hepatic arterial infusion for unresectable liver metastases from colorectal cancer: the end of an era? J Clin Oncol 2007; 25:5649-5654.

118 Kemeny NE, Niedzwiecki D, Hollis DR, et al: Hepatic arterial infusion versus systemic therapy for hepatic metastases from colorectal cancer: a randomized trial of efficacy, quality of life, and molecular markers (CALGB 9481). J Clin Oncol 2006;24: 1395-1403.

119 Kemeny NE, Melendez FD, Capanu M, et al: Conversion to resectability using hepatic artery infusion plus systemic chemotherapy for the treatment of unresectable liver metastases from colorectal carcinoma. J Clin Oncol 2009;27:3465-3471.

120 Huitzil FDCM, Paty P, D’Angelica M, Fong Y, Jarnagin W, Patel D, Kemeny N: Predictive factors for resection of unresectable metastases from colorectal cancer in patients treated with hepatic arterial infusion (HAI) with floxuridine (FUDR) and dexamethasone (DEX) plus IV oxaliplatin (Oxali) and irinotecan (CPT). Proc Am Soc Clin Oncol (Gastrointestinal Symposium), Orlando, 2008.

121 Kemeny N, Huang Y, Cohen AM, et al: Hepatic arterial infusion of chemotherapy after resection of hepatic metastases from colorectal cancer. N Engl J Med 1999;341: 2039-2048.

122 Kemeny NE, Gonen M: Hepatic arterial infusion after liver resection. N Engl J Med 2005;352:734-735.

-123 Stang A, Fischbach R, Teichmann W, Bokemeyer C, Braumann D: A systematic review on the clinical benefit and role of radiofrequency ablation as treatment of colorectal liver metastases. Eur J Cancer 2009; 45: 1748-1756.
124 Wong SL, Mangu PB, Choti MA, et al: American Society of Clinical Oncology 2009 clinical evidence review on radiofrequency ablation of hepatic metastases from colorectal cancer. J Clin Oncol 2010;28: 493-508.

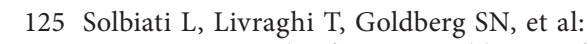
Percutaneous radio-frequency ablation of hepatic metastases from colorectal cancer: long-term results in 117 patients. Radiology 2001;221:159-166.

126 Gillams A, Cassoni A, Conway G, Lees W: Radiofrequency ablation of neuroendocrine liver metastases: the Middlesex experience. Abdom Imaging 2005;30:435-441.

127 Jakobs TF, Hoffmann RT, Trumm C, Reiser MF, Helmberger TK: Radiofrequency ablation of colorectal liver metastases: midterm results in 68 patients. Anticancer Res 2006;26:671-680.

-128 Amersi FF, McElrath-Garza A, Ahmad A, et al: Long-term survival after radiofrequency ablation of complex unresectable liver tumors. Arch Surg 2006;141:581-587; discussion 7-8.

129 Abitabile P, Hartl U, Lange J, Maurer CA: Radiofrequency ablation permits an effective treatment for colorectal liver metastasis. Eur J Surg Oncol 2007;33:67-71.

130 Siperstein AE, Berber E, Ballem N, Parikh RT: Survival after radiofrequency ablation of colorectal liver metastases: 10-year experience. Ann Surg 2007;246:559-565; discussion 65-67.

131 Sorensen SM, Mortensen FV, Nielsen DT: Radiofrequency ablation of colorectal liver metastases: long-term survival. Acta Radiol 2007;48:253-258.

132 Veltri A, Sacchetto P, Tosetti I, Pagano E, Fava C, Gandini G: Radiofrequency ablation of colorectal liver metastases: small size favorably predicts technique effectiveness and survival. Cardiovasc Intervent Radiol 2008;31:948-956.

$>133$ Gillams AR, Lees WR: Five-year survival following radiofrequency ablation of small, solitary, hepatic colorectal metastases. J Vasc Interv Radiol 2008;19:712-717.

-134 Oshowo A, Gillams A, Harrison E, Lees WR, Taylor I: Comparison of resection and radiofrequency ablation for treatment of solitary colorectal liver metastases. $\mathrm{Br} \mathrm{J}$ Surg 2003;90:1240-1243.

135 Aloia TA, Vauthey JN, Loyer EM, et al: Solitary colorectal liver metastasis: resection determines outcome. Arch Surg 2006;141: 460-466; discussion 6-7.

136 White RR, Avital I, Sofocleous CT, et al: Rates and patterns of recurrence for percutaneous radiofrequency ablation and open wedge resection for solitary colorectal liver metastasis. J Gastrointest Surg 2007;11: 256-263. 
-137 Park IJ, Kim HC, Yu CS, Kim PN, Won HJ, Kim JC: Radiofrequency ablation for metachronous liver metastasis from colorectal cancer after curative surgery. Ann Surg Oncol 2008;15:227-232.

138 Hur H, Ko YT, Min BS, et al: Comparative study of resection and radiofrequency ablation in the treatment of solitary colorectal liver metastases. Am J Surg 2009;197:728736.

-139 Pawlik TM, Izzo F, Cohen DS, Morris JS, Curley SA: Combined resection and radiofrequency ablation for advanced hepatic malignancies: results in 172 patients. Ann Surg Oncol 2003;10:1059-1069.

140 Elias D, Baton O, Sideris L, et al: Hepatectomy plus intraoperative radiofrequency ablation and chemotherapy to treat technically unresectable multiple colorectal liver metastases. J Surg Oncol 2005;90:36-42.

- 141 Kornprat P, Jarnagin WR, DeMatteo RP, Fong Y, Blumgart LH, D’Angelica M: Role of intraoperative thermoablation combined with resection in the treatment of hepatic metastasis from colorectal cancer. Arch Surg 2007;142:1087-1092.

142 Abdalla EK, Vauthey JN, Ellis LM, et al: Recurrence and outcomes following hepatic resection, radiofrequency ablation, and combined resection/ablation for colorectal liver metastases. Ann Surg 2004;239:818825; discussion 25-27.

143 Ruers TJ, Joosten JJ, Wiering B, et al: Comparison between local ablative therapy and chemotherapy for non-resectable colorectal liver metastases: a prospective study. Ann Surg Oncol 2007;14:1161-1169.
144 Tomlinson I, Webb E, Carvajal-Carmona $\mathrm{L}$, et al: A genome-wide association scan of tag SNPs identifies a susceptibility variant for colorectal cancer at $8 \mathrm{q} 24.21$. Nat Genet 2007;39:984-988.

145 Berndt SI, Potter JD, Hazra A, et al: Pooled analysis of genetic variation at chromosome 8q24 and colorectal neoplasia risk. Hum Mol Genet 2008;17:2665-2672.

146 Zanke BW, Greenwood CM, Rangrej J, et al: Genome-wide association scan identifies a colorectal cancer susceptibility locus on chromosome 8q24. Nat Genet 2007;39: 989-994.

-147 Tenesa A, Farrington SM, Prendergast JG, et al: Genome-wide association scan identifies a colorectal cancer susceptibility locus on $11 \mathrm{q} 23$ and replicates risk loci at $8 \mathrm{q} 24$ and 18q21. Nat Genet 2008;40:631-637.

148 Broderick P, Carvajal-Carmona L, Pittman AM, et al: A genome-wide association study shows that common alleles of SMAD7 influence colorectal cancer risk. Nat Genet 2007;39:1315-1317.

149 Tomlinson IP, Webb E, Carvajal-Carmona L, et al: A genome-wide association study identifies colorectal cancer susceptibility loci on chromosomes 10p14 and 8q23.3. Nat Genet 2008;40:623-630.

150 Houlston RS, Webb E, Broderick P, et al: Meta-analysis of genome-wide association data identifies four new susceptibility loci for colorectal cancer. Nat Genet 2008;40: 1426-1435.

151 Kida Y, Han YP: MicroRNA expression in colon adenocarcinoma. JAMA 2008;299. 2628; author reply 2628-2629.
152 Valeri N, Croce CM, Fabbri M: Pathogenetic and clinical relevance of MicroRNAs in colorectal cancer. Cancer Genomics Proteomics 2009;6:195-204.

153 Schetter AJ, Leung SY, Sohn JJ, et al: MicroRNA expression profiles associated with prognosis and therapeutic outcome in colon adenocarcinoma. JAMA 2008;299: 425-436.

154 Cohen SJ, Punt CJ, Iannotti N, et al: Prognostic significance of circulating tumor cells in patients with metastatic colorectal cancer. Ann Oncol 2009;20:1223-1229.

155 Leversha MA, Han J, Asgari Z, et al: Fluorescence in situ hybridization analysis of circulating tumor cells in metastatic prostate cancer. Clin Cancer Res 2009;15:20912097.

156 Saltz LB, Cox JV, Blanke C, et al: Irinotecan plus fluorouracil and leucovorin for metastatic colorectal cancer. Irinotecan Study Group. N Engl J Med 2000;343:905-914.

157 De Gramont A, Figer A, Seymour M, et al: Leucovorin and fluorouracil with or without oxaliplatin as first-line treatment in advanced colorectal cancer. J Clin Oncol 2000;18:2938-2947.

158 Van Cutsem E, Kohne CH, Hitre E, et al: Cetuximab and chemotherapy as initial treatment for metastatic colorectal cancer. N Engl J Med 2009;360:1408-1417.

159 Hecht JR, Mitchell E, Chidiac T, et al: A randomized phase IIIB trial of chemotherapy, bevacizumab, and panitumumab compared with chemotherapy and bevacizum$\mathrm{ab}$ alone for metastatic colorectal cancer. J Clin Oncol 2009;27:672-680. 